\title{
Assessment of the risk of cardiovascular and gastric problems in textile mill workers of Pali district in relation to shift work
}

Author for Correspondence :

\section{R. RANAWAT}

Department of Home Science, Jai Narain Vyas University, JODHPUR

(RAJASTHAN) INDIA

Email : raginiranawat20@gmail. com
ABSTRACT : Textile industry touches the lives of all people in one or the other ways. In Rajasthan state particularly, textile mills represent an important economic sector. In Pali district, with highest number of textile mills in the state, the work never stops. It is a round the clock operating sector where shift work is highly prevalent. Different shift work systems have potentially different impacts on the health of the workforce, disturbing the circadian rhythm, an essential biological function and also inducing sleep deprivation. This characteristic makes shift work one of the most widespread work environment risk factor. The disruption of circadian rhythm may have an adverse impact on cardiovascular and gastrointestinal functioning of the body. Right from the secretion of acid to digestion of food, appetite and diet, everything gets disturbed. The present study was conducted in textile mill of Pali city with the objective to study the risk of cardiac and gastric problems in relation to shift work among male workers. Total of 400 male workers were studied, out of which 200 were non-shift workers and 200 were shift workers. Anthropometric measurements, food intake, blood pressure and lipid profile of the subjects were taken along with data on cardiac and gastric problems. The results showed significant difference between $\mathrm{BMI}\left(\chi^{2}=14.2, \mathrm{P}=0.0008\right)$ and waist hip ratio $\left(\chi^{2}=5.2, \mathrm{P}=0.0226\right)$ of shift and non shift workers. Majority $(84.50 \%)$ of the shift workers faced sleep related problems. Results on food intake showed comparatively more deficient daily intake of nutrients like fibre (7.21 g), $\beta$ carotene $(1842.89 \mu \mathrm{g})$, and folic acid $(99.03 \mu \mathrm{g})$ in shift workers with respect to recommended dietary allowances and an overconsumption of fats $(37.72 \mathrm{~g})$. Alcoholism $\left(\chi^{2}=17.3, \mathrm{P}=0.0001\right)$ and smoking habit $\left(\chi^{2}=14, \mathrm{P}=0.0029\right)$ was found to be significantly higher among shift workers. Comparatively higher segment of shift workers suffered from hypertension $(56.0 \%)$, stress $(70.50 \%)$, disturbed appetite $(87.50 \%)$, stomach upsets $(90.0 \%)$, nausea $(88.50 \%)$, heartburn $(85.0 \%)$ and breathlessness $(34.0 \%)$. Shift workers also had higher mean levels of all lipid profile fractions and relatively more subjects fell into the category of high risk (20.50\%) of CVD. Based on the results, it can be concluded that shift work affects sleep, food intake, BMI, WHR, BP, stress levels, alcohol intake, smoking habits and lipid profile of the subjects, thus increasing the risk of health problems like cardiovascular and gastric diseases.

KEY WORDS: Shift work, Textile mills, CVD, Gastric problems, Body mass index, Blood pressure, Lipid profile 